\title{
Comparing outpatient and inpatient utilization rate in physicians, informed healthcare service consumers, and non-physicians, uninformed healthcare service consumers
}

\section{Farnam Mohebi}

Non-Communicable Diseases Research Center, Endocrinology and Metabolism Population Sciences Institute, Tehran University of Medical Sciences https://orcid.org/0000-0002-6181-2008

Elham Ahmadnezhad ( $\square$ elhamahmadnezhad@gmail.com )

Mohammad Ali Mansournia

Department of Epidemiology and Biostatistics, School of Public Health, Tehran University of Medical

Sciences

\section{Reza Majdzadeh}

Department of Epidemiology and Biostatistics, School of Public Health, International Campus, Tehran University of Medical Sciences

Iraj Harirchi

Cencer Research Center, Cancer Institute of Iran, Tehran University of Medical Sciences

\section{Naser Ahmadi}

Non-Communicable Diseases Research Center, Endocrinology and Metabolism Population Sciences Institute, Tehran University of Medical Sciences

\section{Ali Ghanbari}

Non-Communicable Diseases Research Center, Endocrinology and Metabolism Population Sciences Institute, Tehran University of Medical Sciences

\section{Research article}

Keywords: Induced demand, Information asymmetry, Health Care Utilization, Health Policy, Health Care Economics and Organizations, Iran

Posted Date: June 18th, 2020

DOI: https://doi.org/10.21203/rs.3.rs-32835/v1

License: (c) (i) This work is licensed under a Creative Commons Attribution 4.0 International License. Read Full License 


\section{Abstract \\ Background}

Supplier-induced demand(SID)cause a considerable but preventable economic burden on health systems.SID exists when the supplier changes a patient's demand for his greater interest because of their asymmetric medical information. The informed patient is expected to resist demand induction,thus, his amount of utilization would be free of induction.In this study,we aimed to examine the impact of the opportunity of SID,information asymmetry,on healthcare utilization. As the nature of the association of interest could be considered to be the same in variety of contexts, we believe our results are generalizable to other countries as well.

\section{Methods}

We compared the individual outpatient and inpatient utilization rates in randomly chosen physicians(medically-informed)and non-physicians(medically-uninformed)with university degree and same living area in the Tehran province,the capital of Iran.Subjects were chosen by simple random selection with replacement from the relevant phone number list.Phone number lists were extracted from the Tehran province phone number list categorized by occupation. We excluded non-physicians with at least one physician in their close family and medical interns and subjects who did not answer the phone call and were unwilling to cooperate.Negative-binomial was used for comparing incidence rates of utilization(Hurdle in inpatient utilization), adjusted for demographic characteristics, insurance coverage,access to healthcare, and health status as healthcare-utilization-altering factors. The data collection tool consisted of 22 questions and was designed based on the list of the services that are prone to be induced by a supplier.The questionnaire was face-validated and content-validated in face to face interviews.

\section{Results}

In 349 physicians and 295 non-physicians,the adjusted outpatient and inpatient-utilization incidence was higher in non-physicians(incidence-rate-ratio: 1.38 and 3.19,respectively),p-value $<0.05$. The only variable that correlated significantly with utilization rates was the presence of chronic diseases as the incidence rate of inpatient utilization was in patients with chronic conditions was 2.01 times of the individuals without.

\section{Conclusions}

The higher incidence rate of utilization in non-physicians comparing to physicians suggest SID existence and might be caused by information asymmetry and non-physicians' vulnerability for SID,especially that 
utilization-altering factors were considered in the study design and analysis. The findings validate policies to regulate service provision,plan an appropriate payment system, which is mainly fee for service payment in Iran,and increase general population-health information via trusted routes.

\section{Background}

Supplier induced demand (SID) in health economics, is the amount of demand that would have not existed if the patient was fully and symmetrically informed. [1] Due to the precise and exact definition of McGuire 2000, "Physician-induced demand exists when the physician influences a patient's demand for care against the physician's interpretation of the best interests of the patient". [2] The supplier, like physician, encourages the patient to demand greater quantities of health care services and shift his demand curve for the sake of supplier's own financial and non-financial interest. [3] Therefore, information gap between supplier and consumer of a service is the required condition that a supplier could induce the consumer a demand. In result, the informed consumer could resist the induction. This further utilization beyond the interests of the patient, results in welfare loss for the patient, which could be saved without altering or even improving health outcomes of the patient. [3] SID could be investigated using empirical evidence with different study designs like investigating the impact of physician income shocks and difference in physician fees on the amount of provided services, difference in service provision to patients with varying information, and indirect evidence like self-referral frequency in suppliers. [3] The results of demand induction differences among patients with varying information have been contentious; some reported that health care utilization was more among physicians, the informed patients who are supposed to resist the induction, contrary to the primary prediction; physicians would resist any induction and in result would utilize less amount of health services comparing to uninformed patients. [4-8] However, other studies reported significantly higher utilization rates among non-physicianpatients comparing to physician-patients. [9-11]

Iran healthcare system consists of Primary Health Care networks as first level, healthcare and hospital services provided by medical/health specialists as second level, and specialized, consultative healthcare for inpatient services, often through referrals from previous levels and within tertiary hospitals as third level of health service provision. The main provider payment mechanism is historically Fee for Service (FFS) and per-case payments in Iran. Like outpatient services, hospital services include common procedures reimbursed via per-case payment method and other services paid in terms of FFS method whose fee schedules are determined according to relative value units of the year. Moreover, there is no regulatory system monitoring the FFS payment which makes SID happening easier for providers as FFS and the subsequent SID has been argued to be one of main underlying reasons of the increased expenses on health in Iran. [12-14] A few studies have reported the existing evidences of SID in Iran healthcare market, however, none of them assessed the impact of consumer information on the amount of utilized healthcare services. [15-20] In this regard, we aimed the estimate whether informed patients differ in their amount of utilization with uninformed patients. The hypothesis is that the informed patient (physician-patient) resists the induction of a demand, thus, their utilization of healthcare services is their 
actual need and any further utilization in non-physician-patients may be due to induced demand, especially if the altering characteristics of actual healthcare need are considered.

\section{Methods}

\subsection{Study Design:}

This study was performed in the Tehran province, the capital of Iran, to compare the mean individual outpatient and inpatient utilization rates in physicians (informed consumer) and non-physicians (uninformed consumer) after controlling for conditions with probable impact on health care need and utilization.

\subsection{Population:}

Study population consisted of the physicians and non-physicians of the Tehran province who were randomly chosen. Subjects who did not answer the phone call and were unwilling to cooperate. In nonphysicians, subjects who had at least one physician in their close family (parents, children, siblings, spouse) or were a medical intern, were excluded as well, because their health information, and in result healthcare utilization, is probably different of other non-physicians.

\subsection{Data Collection}

Variables were as followings

1) Demographic: age, gender, occupation, education, marital status, living region, and income (low, lower middle, upper middle, and high based on the current currency of the country);

2) Insurance coverage: basic insurances in Iran consist of social insurances that covers more than $90 \%$ of Iranian population.

3) Access to healthcare: the least time required for achieving the nearest healthcare provision center, and number of people living permanently in the household;

4) Health status: self-perceived health status (great, good, not bad, bad) and presence of a chronic condition (including any of the following conditions for at least 3 months that is diagnosed by a physician; any metabolic, cardiovascular disease, any kind of disability, hematologic disease, psychiatric disease, chronic infection, rheumatologic disorder, or other specified chronic disease);

We expected that age, sex, income, marital status, insurance coverage, and impaired health have a positive effect on utilization rate, opposing to minutes to the nearest healthcare center and number of 
people living in the household (by reducing the monetary and non-monetary sources allocated to each person in the family) which reflect an impaired access to healthcare. [5, 21, 22]

Outpatient and inpatient utilization rates were outcomes of interest. Outpatient utilization per patient consisted of number of imaging and laboratory services, physiotherapy sessions, and medicine purchasing with or without prescription in the last month multiplied by 12 besides number of outpatient surgeries, pap smear or mammography, and endoscopies and colonoscopies in the last year for each patient. Because of physicians bring able to purchase medicines without any prescription in Iran, we included medicine purchasing without prescription as well. General physician visit, specialists visits, outpatient emergency room visits, and injections were not calculated in the final outpatient utilization rate, because many physicians perform self-prescription [23] and including them in the final outpatient utilization rate might have resulted in an overestimated difference. Inpatient utilization consisted of number of admissions in the last year per patient. Being admitted was defined as an official inhabitancy in a hospital for at least 6 hours based on Iran Health Insurance Organization definition. [24] For admissions, patients were asked to report how many times they have been admitted in the last year in any of the following wards; surgery, internal medicine, obstetrics and gynecology, emergency room, Intensive Care Unit or Coronary Care Unit, or any other ward.

\subsection{Data Collection Tool}

The questionnaire used in this study was developed for this study (supplementary file 1); The telephonesurvey questionnaire consisted of 21 questions and was designed based on the list of the services that are prone to be induced by a supplier, and therefore different in physicians and non-physicians, according to previous literature $[25,26]$ and experts' opinion. Possible individual characteristics that could affect healthcare utilization were also included as explained in the previous section. The questionnaire was face-validated and content-validated in face to face interviews with 5 experts and 5 physicians and 5 nonphysicians with university degree. The pilot phase was performed in 21 individuals ( 11 physicians and 10 non-physicians) and the Cronbach's alpha based on a 10-day-apart test-retest was 0.845. [27] Additionally, the Pearson correlation coefficient was calculated for each variable; all were perfectly correlated except self-perceived health $(0.79, \mathrm{p}$-value $<0.05)$.

\subsection{Sampling Method}

To our knowledge, there were no studies specifically reporting the incidence rate ratio in physicians vs non-physicians, therefore, we were unable to calculate the sample size based on the relevant formula. Thus, we utilized the nearest sample size of the most methodologically similar study to ours. [4] Subjects were chosen by simple random selection with replacement from the relevant phone number list. Phone number lists were extracted from the Tehran province phone number list categorized by occupation. Physicians were chosen as general practitioners and specialists. Non-physicians were chosen as subjects who had any kind of job requiring university degree; including psychologists, lawyers, statisticians, 
accountants, etc. Further control questions examining the individual education and occupation were included in the questionnaire, but not inserted in the final model for analysis. Physician and nonphysicians were matched on their living area based on the first 2 digits of their phone number, due to different socioeconomical status of different living areas in Tehran. In details, for every physician who was interviewed, among the non-physicians' phone number lists, the ones who had a phone number that was the same in the first two digit as the interviewed physician, non-physicians were contacted till they had the inclusion criteria and they were willing to cooperate.

\subsection{Statistical Analysis}

All baseline characteristics of the populations are reported in frequency of subgroups for categorizing variables and mean and standard deviation for numeric variables. The inpatient and outpatient utilization mean rates are reported in different subgroups of the participants as well.

For further analysis, as the outcome was count measure, we chose regression models that are specified for count data. In further analysis of the outpatient utilization rate, as we wanted to incorporate the overdispersion (mean and variance of the distribution were not equal), we used negative binomial model. In the analysis of inpatient utilization rate, we encountered excess zeros (the frequency of not being admitted in the last year was more than $50 \%$ ) beside over-dispersion, and according to the nature of the data, we utilized hurdle negative binomial model.[28]

To compare whether the outcome of hurdle regression model was different from regular negavive binomial model, we performed vuong test to the model outputs ( $p$-value < 0.05). [29] All variables, except education, occupation, and living area because of being control variables of the inclusion criteria, were inserted in the final model. [30] For sensitivity analysis, all analysis was done excluding outpatient surgery; because its nature is different of other outpatient services, there is a high probability that the main proportion of outpatient surgeries are cosmetic procedures, and finally, the outpatient surgeries that were utilized by physicians might have been inpatient type of surgeries but utilized as an outpatient service because physicians avoided to be admitted. Besides, the analysis were reported with exclusion of office visits and injections, that are probable to be performed by physicians themselves. Moreover, obstetrics and gynecology admissions were omitted from inpatient utilization, because they are mostly provided for delivery and cannot be induced or neglected. Finally, subjects who did not report any utilization, whether outpatient or inpatient, were excluded from the analysis to reduce the impact of probable underutilization in physicians on the final comparison. Utilizing the "Matchlt"[31] and "Zelig"[32, 33] packages in $R$ for nearest neighbor matching, we also matched on the residence area before the regression results and the results did not differ significantly (each individual could be matched to more than one individual in the matching population). The general patterns remained the same for each step of sensitivity analysis, therefore, the details are not reported in this article.

\section{Results}


648 patients were included: $53.85 \%$ of the population were physicians $(n=349)$ and $46.14 \%$ were nonphysicians $(n=295)$. The general chacateristics of physicians and non-physicians are presented in Table 1: physicians were more married (78.8\% vs $65.0 \%)$, had higher income more often $(56.4 \%$ vs 6.8$)$, had a chronic disease less often $(7.4 \%$ vs. $33.22 \%)$, had less family members ( $2.7 \pm 1.1$ vs $2.9 \pm 1.0)$, were slightly older ( $41.0 \pm 8.4$ vs $39.7 \pm 10.8$ years) and closer to healthcare centers ( $20.3 \pm 11.0$ vs $21.5 \pm 17.8$ minutes).

Table 1

General characteristics of the physician-patients and non-physician-patients

\begin{tabular}{|c|c|c|c|}
\hline Variable & Categories & $\begin{array}{l}\text { Physician(n } \\
=350)\end{array}$ & $\begin{array}{l}\text { Non- } \\
\text { physician(n } \\
=295)\end{array}$ \\
\hline Gender & Male $\%$ & 60.6 & 57.7 \\
\hline Marital status & Married \% & 78.8 & 65.0 \\
\hline \multirow[t]{4}{*}{ Income } & Low \% & 2.3 & 23.1 \\
\hline & $\begin{array}{l}\text { Lower } \\
\text { middle \% }\end{array}$ & 11.2 & 43.2 \\
\hline & $\begin{array}{l}\text { Upper } \\
\text { middle \% }\end{array}$ & 30.1 & 26.9 \\
\hline & High \% & 56.4 & 6.8 \\
\hline \multirow[t]{4}{*}{ Self-perceived health } & Bad \% & 3.0 & 4.9 \\
\hline & Not bad \% & 23.1 & 21.4 \\
\hline & Good \% & 62.6 & 56.4 \\
\hline & Great \% & 11.2 & 17.3 \\
\hline Chronic disease & Present \% & 7.4 & 33.22 \\
\hline Basic insurance coverage & Covered \% & 97.41 & 97.92 \\
\hline Age (year) & $\begin{array}{l}\text { Mean } \pm \\
\text { SD }\end{array}$ & $41.0 \pm 8.4$ & $39.7 \pm 10.8$ \\
\hline Family size (member) & $\begin{array}{l}\text { Mean } \pm \\
\text { SD }\end{array}$ & $2.7 \pm 1.1$ & $2.9 \pm 1.0$ \\
\hline $\begin{array}{l}\text { Distance to the nearest healthcare center (minutes to } \\
\text { the nearest healthcare center) }\end{array}$ & $\begin{array}{l}\text { Mean } \pm \\
\text { SD }\end{array}$ & $20.3 \pm 11.0$ & $21.5 \pm 17.8$ \\
\hline
\end{tabular}

Generally, the outpatient utilization was significantly different among physicians and non-physicians $(0.85(0.79-0.91))$ vs $1.10(0.98-1.22), \mathrm{p}$-value < 0.05$)$, however, the difference in inpatient utilization was higher (physicians: 0.18 (0.12-0.24) admission per year; non-physicians: $0.51(0.40-0.61), p$-value < 
0.05) (Table 2). Additionally, among different variables in the studied population, chronic disease was the only variables that associated significantly with inpatient utilization (Table 2). 
Table 2

Mean of outpatient and inpatient healthcare utilization rate in subgroups of the study population

\begin{tabular}{|c|c|c|c|}
\hline & & $\begin{array}{l}\text { Outpatient (per } \\
\text { month) }\end{array}$ & Inpatient (per year) \\
\hline & & \multicolumn{2}{|c|}{ Mean utilized services rate $(95 \% \mathrm{Cl})$} \\
\hline & & $0.96(0.90-1.02)$ & $0.33(0.27-0.39)$ \\
\hline \multirow[t]{2}{*}{ Information asymmetry } & $\begin{array}{l}\text { Physician-patients } \\
\text { (0) }\end{array}$ & $\begin{array}{l}0.853(0.795- \\
0.911)^{\star \star \star}\end{array}$ & $0.18(0.12-0.24)^{\star \star \star}$ \\
\hline & $\begin{array}{l}\text { Non-physician- } \\
\text { patients }\end{array}$ & $1.10(0.98-1.22)^{\star \star \star}$ & $0.51(0.40-0.61)^{\star \star \star}$ \\
\hline \multirow[t]{2}{*}{ Gender } & Male & $0.982(0.902-1.061)$ & $0.374(0.294-0.453)$ \\
\hline & Female & $0.945(0.836-1.054)$ & $0.273(0.191-0.355)$ \\
\hline \multirow[t]{2}{*}{ Marital status } & Single (0) & $1.019(0.893-1.145)$ & $0.295(0.194-0.396)$ \\
\hline & Married & $0.948(0.872-1.025)$ & $0.35(0.279-0.421)$ \\
\hline \multirow[t]{4}{*}{ Income } & Low & $1.1(0.889-1.311)$ & $0.307(0.151-0.462)$ \\
\hline & Lower middle & $0.994(0.853-1.136)$ & $0.422(0.293-0.55)$ \\
\hline & Upper middle & $0.949(0.821-1.078)$ & $0.364(0.248-0.48)$ \\
\hline & High & $0.924(0.836-1.013)$ & $0.244(0.161-0.328)$ \\
\hline \multirow[t]{4}{*}{ Self-perceived health } & Bad & $0.833(0.391-1.276)$ & $0.565(0.178-0.953)$ \\
\hline & Not bad & $0.987(0.818-1.157)$ & $0.436(0.286-0.586)$ \\
\hline & Good & $0.977(0.895-1.058)$ & $0.273(0.203-0.343)$ \\
\hline & Great & $0.88(0.733-1.026)$ & $0.337(0.176-0.498)$ \\
\hline \multirow[t]{2}{*}{ Chronic disease } & Not present & $0.945(0.877-1.013)$ & $\begin{array}{l}0.238(0.187- \\
0.29)^{\star \star \star}\end{array}$ \\
\hline & Present & $1.059(0.884-1.234)$ & $\begin{array}{l}0.718(0.523- \\
0.912)^{\star \star \star}\end{array}$ \\
\hline \multirow[t]{3}{*}{ Basic insurance coverage } & Not present & $1.072(0.626-1.519)$ & $0.467(0.005-0.928)$ \\
\hline & Present & $0.967(0.902-1.033)$ & $0.33(0.271-0.389)$ \\
\hline & & \multicolumn{2}{|l|}{ Incidence rate ratios } \\
\hline Age & +1 year & 0.998 (SE:1.004) & 0.977 (SE:1.013) \\
\hline Family size & + 1 member & 0.985 (SE:1.036) & 0.888 (SE:1.137) \\
\hline $\begin{array}{l}\text { Least distance to } \\
\text { healthcare }\end{array}$ & +1 minute & 1.001 (SE:1.003) & 0.993 (SE:1.007) \\
\hline
\end{tabular}


In the final adjusted model for outpatient and inpatient healthcare utilization rate, being a non-physician versus physician was significantly associated with higher rate of utilization in outpatient and inpatient setting with respective incidence rate ratios of 1.38 (increased from1.29) and 3.19 (increased from 3.01), presented in Table 3. Moreover, having a chronic disease association with inpatient utilization remained significant after adjusting for all variables.

Table 3

Adjusted incidence rate ratio of outpatient and inpatient utilization in non-physicians vs. physicians

\begin{tabular}{|c|c|c|c|}
\hline & & Outpatient Utilization & Inpatient Utilization \\
\hline Variables & Categories & $\begin{array}{l}\text { Adjusted incidence rate } \\
\text { ratios }\end{array}$ & $\begin{array}{l}\text { Adjusted incidence rate } \\
\text { ratios }\end{array}$ \\
\hline $\begin{array}{l}\text { Information } \\
\text { asymmetry }\end{array}$ & $\begin{array}{l}\text { Non-physician vs. } \\
\text { physician }\end{array}$ & $1.38^{\star \star \star}$ & 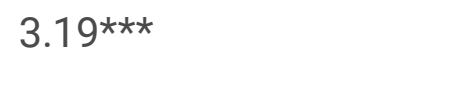 \\
\hline Gender & Female vs. male & 0.97 & 1.13 \\
\hline Marital status & Married vs. single & 0.93 & 1.12 \\
\hline \multirow[t]{3}{*}{ Salary } & Lower middle vs. low & 0.89 & 1.35 \\
\hline & Upper middle vs. low & 0.95 & 1.67 \\
\hline & High vs. low & 1.05 & 1.56 \\
\hline \multirow[t]{3}{*}{ Perceived health } & Great vs. Bad & 1.11 & 0.67 \\
\hline & Good vs. bad & 1.07 & 0.49 \\
\hline & Not bad vs. Bad & 0.93 & 0.62 \\
\hline Chronic disease & $\begin{array}{l}\text { Present vs. Not } \\
\text { present }\end{array}$ & 0.96 & $2.01^{\star \star \star}$ \\
\hline $\begin{array}{l}\text { Basic insurance } \\
\text { coverage }\end{array}$ & $\begin{array}{l}\text { Present vs. Not } \\
\text { present }\end{array}$ & 0.93 & 0.44 \\
\hline Age & +1 year & 1 & 1.01 \\
\hline Family size & + 1 member & 0.96 & 1.12 \\
\hline $\begin{array}{l}\text { Least distance to } \\
\text { healthcare }\end{array}$ & +1 minute & 1 & 1.01 \\
\hline 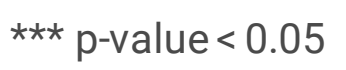 & & & \\
\hline
\end{tabular}




\section{Discussion}

The hypothesis of our study was that whenever the information is symmetric between the supplier and the patient, supplier induced demand could not happen. Therefore, the rate of health care services utilized in physicians could be considered as their actual need, and any further utilization in non-physicians with similar health care needs might be caused by SID. In other words, physician-patient utilization rate is considered as "gold standard". [9] Considering physicians' utilization as gold standard does noes imply that this is the appropriate care, as the outcomes of care are not considered and evaluated, it solely indicates a standard rate for detecting evidences of possible SID. Our findings suggested the existence of SID in Iranian healthcare market; non-physicians with asymmetric information to the provider utilized more services than physicians that were similar to the provider in terms of medical information. When adjusted for probable conditions that could alter healthcare utilization, health care utilization remined higher in non-physicians than physicians with incidence rate ratio of 1.38 (outpatient) and 3.19 (inpatient).

Previous reports yield evidence of SID in Iran healthcare market as well. The number of physicians in a particular location in Iran healthcare market was reported to have positive correlation with the amount of provided services and this correlation positively increased with higher price of the health care service both in outpatient and inpatient setting. [15] Additionally, physicians who were not a permanent salary-based employee tended to prescribe more lab tests and spend less time with their patients. [16] When veteran patients who were and were not covered by a complementary insurance plan were compared, physicians suggested more visits to patients who had insurance coverage [17], indicating an evidence of supplierinduced demand because patients, who do not experience financial pressure of excess utilization due to their insurance coverage, would be more probable to accept demand induction. [18] Our results were also in accordance to previous international reports; in a population-based study of Taiwan, physicians utilized less healthcare than comparison non-physician subjects [34], female physicians and their relatives had lower cesarean delivery rate comparing to other women [35], and physicians' risk of hospitalization, all caused and major individual causes, was significantly lower than general population [10]. In a random sample of Blue Cross/Blue Shield providers of Rhode Island, physicians had lower use of formal healthcare services comparing to chiropractors, dentists, optometrists, and podiatrists. [36] In another report from California, non-physicians Cesarean-section rate was $7 \%$ more than physicians, controlled for demographics and clinical risks. [37] Opposing to our observations, physicians were as likely as non-physicians to consume health services in a national household survey of the Center for Health Administration Studies at the University of Chicago [5], however, they solely studied office visits, while other SID-susceptible outpatient services, like laboratory tests and imaging services, were not included in the analysis. Additively, the probability of using a medical care increased with patient information based on answers to a supplemental health opinion questionnaire. In spite of that, they recommended that the low consumption in poorly informed consumers might be caused by their underestimating the impact of medical services for improving their illness. [38] Finally, physicians had higher national rates of surgical services comparing to other United States population [4]. As they did not 
investigate the economic barriers to utilization in non-physician population, the difference might have been caused by dissimilar financial access to services.

There are probable reasons for the observed pattern in our study; first of all, physicians might have not utilized adequate healthcare services because physicians seem to be neglecting and reluctant in seeking appropriate medical care. [39] However, the better self-perceived health status in physicians and the much lower prevalence of any chronic disease in them suggest good health habits in our population. Secondly, the extra amount of services utilized in non-physicians might be caused by higher levels of supply induction by consumer, probably due to lower health literacy and less appropriate physician rapport. Notable, the non-physicians in our study were individuals with university degree and they possibly could communicate better than the general population with the healthcare provider.[40,41] Besides, university education is reported to positively correlate with health literacy. [42] Another possible reason contributing to more health service utilization in non-physicians might be their higher actual needs. This could be the result of better access to healthcare and beneficial health behaviors in physicians. [10] Moreover, physicians are required to be healthy for active practicing. [10] But as we conducted a multivariate analysis and adjusted the results for access to healthcare and health status, the aforementioned differences' impact on healthcare utilization is controlled and the results are adjusted for them. And finally, and according to our hypothesis, the higher utilization amount in non-physician-patients might be caused by the presence of information asymmetry and their vulnerability to be induced about the services that does not result in the best outcome with the least cost. It is mentionable that Tehran has high occupancy rate of hospital beds and the healthcare system of the city provides services to patients referred from other cities, which decreases the probability of unnecessary inpatient utilization.

First of all, the nature of the association of supplier induced demand and information asymmetry could be considered to be the same in variety of contexts, thus, we believe our results are generalizable to patients in other countries and other contexts as well and the driven conclusion is not limited to the directly studied population. In this study, we tried to meet many possible factors that could alter patients need for healthcare services including education level, age, gender, marital status, number of family members, chronic disease presence, insurance coverage , income, healthcare access, and self-perceived health. [26] The random sampling of individuals controlled a considerable part of selection bias. Moreover, we omitted the office and emergency room visits in sensitivity analysis because they are likely to be accomplished by self-prescribing in physicians [23]. Furthermore, non-physicians who had a physician in their first relatives were excluded because their utilization might be different from regular non-physicians. [5] As the survey was performed with the same procedure for all subjects, our study is free of inter-subject variations in data gathering. Yet, our study faced limitations. First, we investigated retrospective self-reported utilization cross-sectionally which might be altered by recall bias. The telephone survey, despite being easy to perform, is inclined with coverage errors, since who could not be reached by telephone, might have a lower socioeconomic status and non-responders are unknown in telephone surveys.[43] Some subpopulations are less likely to get reached by telephone, including elderly, young adults, and sick people. Telephone directories might not be comprehensive and some people may not be listed on them. Especially considering that the unlisted people might differ in the variable of 
interest with listed people, the result might get biased. Generally, the response rate is lower in telephone surveys which result in higher relative expense per completed interview. And finally, telephone surveys are limited in the question types, number of questions, and method of data gathering. [44] However, the key variable, utilization rate, is unlikely to be different among non-respondents and respondents, additionally, we were not able to analyze the variables affecting utilization rate due to limitations of telephone survey and they were all missing when a person was not willing to response or did not answer the phone-call. In spite of the fact that the actual amounts of utilization might differ if it was recorded objectively and via different survey methods, the method was the same in two groups and in result the difference is expected to remain constant. Moreover, comparing costs alongside with rate of utilization could have improved the strength of the conclusion. Additionally, we did not investigate mental health and dentistry services, which could have presented an opposing pattern due to high prevalence of mental disorders in physicians. [10] However, including dentistry services could have enlarged the difference because they are highly susceptible to demand induction in Iran. Available time and attitude for seeking healthcare services, other health related behaviors, service and administration access siding physical access to healthcare services could impact healthcare utilization, which were not investigated in our study. But health status and other aspects of access to healthcare was considered as their proxy. Our limited sample size and population determines the need for further and larger studies. Despite this requirement, the random chosen sample make the results almost generalizable. And finally, the cross-sectional investigation of the number of admissions per year was the only estimation of inpatient utilization that did not contain times a patient needed hospitalization, length of stay, and utilized services during hospitalization.

From a policy perspective, our findings validate the requirement of policies addressing SID. The existence of supplier induced demand in Iranian healthcare market is mainly caused by inappropriate patients' request, excessive trust in physicians, patients' desire to utilize charge-free services more, low health literacy, and last but not least, unregulated access to general physicians and specialists. $[19,20]$ Beside SID, not having an efficient referral system could result in non-physicians' misuse or overuse of services because it takes time and utilization for them to meet the physician with the appropriate specialty regarding their condition. Consequently, the interventions should target appropriate information increasing strategies in general population alongside with payment method reforms to change the SIDsusceptible infrastructure of Iran. Primary care coordination could decrease the inappropriate health service utilization in unaware and confused patients. [45] Furthermore, an established and reliable national resource of information and well-designed decision aids for patients could reduce the vulnerability of uninformed patients to SID. [45] Most importantly, a specialized healthcare workforce could be trained for navigating appropriate information, because patients cannot decide on their own and they might be puzzled in large amount of data provided by central resources of information. [45] Additionally, most of the information is provided by internet, which its access is lowest among lower socioeconomic groups and the elderly, who their need for information is the highest. On top of that, the provided information is probably affected by market preferences. This issue brings up the major role of government for controlling the provided information. [45] The role of the physicians must not be 
forgotten; changing to an appropriate payment system from FFS for physicians and specified ethical trainings in early years of medical school can alter the physicians' distinction for inducing demands. Moreover, protecting physicians for liability risks, while protecting patients interests, could decrease SID. [46] And last but not least, we require wider-scale studies to enlighten the drivers of SID in providers as well as SID-prone services.

\section{Conclusions:}

Taken together, the higher adjusted rate ratio of utilization in non-physicians (uninformed patients) comparing to physicians (informed patients) might be caused by non-physicians' vulnerability for SID as likely as other factors including different behaviors and different needs among two groups. However, due to preventable costs of induced demand in non-physicians, controlling policies are called to increase medical information of non-physicians via regulated pathways and appropriate strategies and modify provider payment systems alongside with education.

\section{Abbreviations}

SID

Supplier-induced demand

FFS

Fee for Service

\section{Declarations}

\subsection{Ethics approval and consent to participate}

The research involved human paticipants with no intervention. An oral consent was taken from the participants who were interviewed via telephone. The study was approved by the institutional review boards (IRB) at ethics committee of Tehran University of medical sciences

(IR.TUMS.MEDICINE.REC.1397.308).

\subsection{Consent for publication}

Not applicable

\subsection{Availability of data and materials}

The data is available upon request to the corresponding author.

\subsection{Competing interests}

The authors declare that they have no competing interests. 


\subsection{Funding}

This study was funded by National Institute of Health Research (NIHR), Tehran University of Medical Sciences, which had no role in the design of the study and collection, analysis, and interpretation of data and in writing the manuscript.

\subsection{Authors' contributions}

FM designed the theoretical framework of the study with the supervision of EA, RM, and IH. FM and EA designed the data collection tool and collected the data. FM cleaned the data with the supervision of EA. FM analyzed the data with the supervision of MAM and consultancy of NA and AGh. FM framed the interpretation of the results with the supervision and guidance of $\mathrm{RM}$ and $\mathrm{IH}$. All authors commented on the final manuscript, FM applied the comments, and all authors approved of the version to submit.

\subsection{Acknowledgements}

The authors appreciate the cooperation of the participants.

\section{References}

1. Cavanagh SJ. Economics of Health Care Financing: The Visible Hand. J Adv Nurs. 1993;18(12):2015-5.

2. McGuire TG. Physician agency. Handbook of health economics, 2000. 1: p. 461-536.

3. Johnson E. Physician-Induced Demand. Encyclopedia of Health Economics. Cambridge: Elsevier; 2014.

4. Bunker JP, Brown BW Jr. The physician-patient as an informed consumer of surgical services. N Engl J Med. 1974;290(19):1051-5.

5. Hay J, Leahy MJ. Physician-induced demand: an empirical analysis of the consumer information gap. Journal of Health Economics. 1982;1(3):231-44.

6. Isaacs A, Britton A, McPherson K. Utilisation of hormone replacement therapy by women doctors. BMJ. 1995;311(7017):1399-401.

7. McNagny SE, Wenger NK, Frank E. Personal use of postmenopausal hormone replacement therapy by women physicians in the United States. Ann Intern Med. 1997;127(12):1093-6.

8. Dugowson CE, The use of obstetric technology in physician families in King County, Washington. 1986, University of Washington.

9. Domenighetti G, et al. Revisiting the most informed consumer of surgical services: the physicianpatient. Int J Technol Assess Health Care. 1993;9(4):505-13.

10. Lin CM, et al. Risks and causes of hospitalizations among physicians in Taiwan. Health services research. 2008;43(2):675-92. 
11. Currie J, Lin W, Zhang W. Patient knowledge and antibiotic abuse: Evidence from an audit study in China. J Health Econ. 2011;30(5):933-49.

12. Dijk CE, et al. Moral Hazard And Supplier-Induced Demand: Empirical Evidence In General Practice. Health Econ. 2013;22(3):340-52.

13. Arrieta A. Health reform and cesarean sections in the private sector: the experience of Peru. Health Policy. 2011;99(2):124-30.

14. Babashahy S, et al., Towards reforming health provider payment methods: evidence from Iran. Health Scope, 2017. 6(1).

15. Varharami V. Physician Induced Demand Journal of Healthcare Management. 2010;2:37-42.

16. Abdoli G, Varharami V. The Role of Asymmetric Information in Induced Demands: A Case Study of Medical Services. Journal of Health Administration. 2011;43(14):37-42.

17. Mahbobi $M$, et al. Supplemental insurances and Induced demand in chemical veterans. Iranian Journal of War Public Health. 2010;2(4):18-22.

18. Abdoli G. Supplier Induced Demand and the Underlying Asymmetry Information between Physician and Patient. Journal of Economic Research, 2005. 40(1).

19. Keyvanara M, et al. Experts about Main Causes of Induced Demand: a Qualitative Study. Health Systems Research Journal. 2014;16(4):317-28.

20. Khorasani E, et al. Role of Patients in Induced Demand from Experts' Perception:A Qualitative Study. J Qual Res Health Sci 2014. 2014;2(4):336-45.

21. Feldstein MS. The rising price of physician's services. The Review of Economics and Statistics, 1970: p. 121-133.

22. Aday LA, Andersen R, Fleming GV. Health care in the US: Equitable for whom? 1980.

23. Hem E, et al. Self-prescribing among young Norwegian doctors: a nine-year follow-up study of a nationwide sample. BMC Med. 2005;3(1):16.

24. Poorasl AM, et al. Substance abuse in Iranian high school students. Addictive behaviors. 2007;32(3):622-7.

25. Saini V, et al. Addressing overuse and underuse around the world. The Lancet. 2017;390(10090):105-7.

26. Freebairn J. Evaluation of the Supplier-Induced Demand for Medical Care Model. Aust Econ Rev. 2001;34(3):353-5.

27. Cronbach LJ. Coefficient alpha and the internal structure of tests. psychometrika. 1951;16(3):297334.

28. Zeileis A, Kleiber C, Jackman S. Regression models for count data in R. Journal of statistical software. 2008;27(8):1-25.

29. $\mathrm{He} \mathrm{H}$, et al. A test of inflated zeros for Poisson regression models. Stat Methods Med Res. 2019;28(4):1157-69. 
30. Figueiredo Filho DB, et al. When is statistical significance not significant? Brazilian Political Science Review. 2013;7(1):31-55.

31. King G, et al., Matchlt: nonparametric preprocessing for parametric causal inference. 2011.

32. Imai K, King G, Lau O. Toward a common framework for statistical analysis and development. Journal of Computational Graphical Statistics. 2008;17(4):892-913.

33. Choirat C, Imai HJ, King K, Lau G O. Zelig: Everyone's Statistical Software. Version 5.1.6.1. 2018 20190613]; Available from: http://zeligproject.org/.

34. Chiu Y-L, et al. Healthcare service utilization for practicing physicians: A population-based study. PloS one. 2016;11(1):e0130690.

35. Chou YJ, et al. Do Physicians and Their Relatives Have a Decreased Rate of Cesarean Section? A 4Year Population-Based Study in Taiwan. Birth. 2006;33(3):195-202.

36. Wachtel TJ, et al. Physicians' utilization of health care. J Gen Intern Med. 1995;10(5):261-5.

37. Johnson EM, Rehavi MM. Physicians treating physicians: Information and incentives in childbirth. American Economic Journal: Economic Policy. 2016;8(1):115-41.

38. Kenkel D. Consumer health information and the demand for medical care. The Review of Economics and Statistics, 1990: p. 587-595.

39. Daga S. Who will Care for the Doctor's Health?

40. Lee SJ, et al. Enhancing physician-patient communication. ASH Education Program Book. 2002;2002(1):464-83.

41. Willems $S$, et al. Socio-economic status of the patient and doctor-patient communication: does it make a difference? Patient Educ Couns. 2005;56(2):139-46.

42. Jansen $T$, et al. The role of health literacy in explaining the association between educational attainment and the use of out-of-hours primary care services in chronically ill people: a survey study. BMC Health Serv Res. 2018;18(1):394.

43. Rosenbaum DP, Lavrakas PJ. Self-reports about place: The application of survey and interview methods to the study of small areas, in Crime and place. NY: Criminal Justice Press and Police Executive Research Forum Monsey; 1995. pp. 285-314.

44. De Leeuw ED, Data quality in mail, telephone and face to face surveys. 1992: ERIC.

45. Retchin SM. Overcoming information asymmetry in consumer-directed health plans. American Journal of Managed Care. 2007;13(4):173.

46. Blomqvist $\AA$. The doctor as double agent: Information asymmetry, health insurance, and medical care. Journal of Health Economics. 1991;10(4):411-32.

\section{Supplementary Files}

This is a list of supplementary files associated with this preprint. Click to download. 
- supplement4.docx

Page 18/18 